\title{
Evaluation of Cassava (Manihot esculenta Crantz) Genotypes for Total Cyanide Content, Storage Tuber and Starch Yield in South Western Ethiopia
}

\author{
Tewodros Mulualem ${ }^{1, ~}$, Neim Semman ${ }^{1}$, Getachew Etana ${ }^{1}$, Shamil Alo ${ }^{2}$ \\ ${ }^{1}$ Jimma Agricultural Research Center, Jimma, Ethiopia \\ ${ }^{2}$ Tepi National Spice Research Center, Tepi, Ethiopia
}

Email address:

tewodrosmulualem@gmail.com (T. Mulualem)

${ }^{*}$ Corresponding author

To cite this article:

Tewodros Mulualem, Neim Semman, Getachew Etana, Shamil Alo. Evaluation of Cassava (Manihot esculenta Crantz) Genotypes for Total Cyanide Content, Storage Tuber and Starch Yield in South Western Ethiopia. International Journal of Biomedical Materials Research. Vol. 8, No. 2, 2020, pp. 14-19. doi: 10.11648/j.ijbmr.20200802.11

Received: January 8, 2020; Accepted: February 25, 2020; Published: August 5, 2020

\begin{abstract}
Cassava (Manihot esculenta) is one of the main food crops that significantly contribute to food security and poverty alleviation in South and Southwest Ethiopia. Cyanide present in cassava roots poses a health challenge in the use of cassava for food. It is therefore important to identify the sweet and bitter types for food and industry. In this study, 11 farmers preferred genotypes were assessed for storage tuber yield, cyanide content and starch contents at Jimma, Metu and Tepi during 2015-2017 cropping seasons. From the genotypes analyzed, AAGT-108 $(128.35 \mathrm{mg} / \mathrm{kg})$ and AAGT-189 $(118.5 \mathrm{mg} / \mathrm{kg}) \mathrm{are}$ identified for bitter type (high HCN content). Based on storage tuber yield, genotype AAGT-108, AAGT-189 and AAGT 192 produced the highest tuber yield in all tested locations. The starch content varies from 5.11 (Qulle at Metu) to 18.40 (AAGT108 at Tepi). Similarly, genotypes AAGT-108, AAGT-189 and AAGT-192 are the best materials at Jimma as compared to others and gave the mean starch content of 15.22, 16.98 and $16.61 \%$, respectively. Based on the overall result of hydrogen cyanide and starch contents, genotype AAGT-108 and AAGT-189 are recommended for bitter type (high HCN content). On contrary, the rest of genotypes have sweet type due to low hydrogen cyanide content below $100 \mathrm{mg} / \mathrm{kg}$ and are recommended for human consumption.
\end{abstract}

Keywords: Cassava, Cyanide, Starch, Storage Tuber, Yield

\section{Introduction}

Cassava (Manihot esculenta Crantz,) is the sixth most important food crop globally, in terms of annual production [13]. The crop is mainly grown in the tropics, including subSaharan Africa, Asia, the Pacific Islands, and Central and South America [19] for staple food of an estimated 800 million people worldwide [14]. The crop have ability to survive adverse conditions such as infertile soil, drought, pests and diseases $[9 ; 4]$ and plays several important roles in Africa serving as a rural staple food, famine-reserve crop, cash crop for households and as a raw material for feed and industrial manufacturing [22]. It has been identified as a potentially valuable source of food for addressing food security in developing countries [20] and a major source of food calories for about two of every five Africans [24]. Although reliable statistical information on the distribution and production of cassava in Ethiopia is lacking, the crop has been cultivated, particularly, in the South, South West, and Western parts to overcome hunger and make a significant contribution in the diets of the people [29].

The starchy tuberous roots are the main food source, which are high amount of carbohydrates, fibers, and low level fats and protein, a good proportion of essential amino acids which make them a good dietary source [20]. Conversely, the wider utilization of cassava in Ethiopia is inadequate; due to information on the biochemical composition of cassava is meager. Further, limited exposure to high doses of hydrogen cyanide is a health risk in major growing regions where cassava is a staple food source [16]. Besides, cassava in itself 
is not a balanced food and malnutrition occurs when cassava is consumed alone as staple food. Studies of nutritional composition on cassava as a food are considerable significance since it may help to identify long forgotten food resource [27]. In this regards, few attempt was made to understand the proximate composition and anti-nutritional factors of the underutilized tubers of cassava to make edible tubers as the safe food sources for mass consumption [26]. In contrast to cultivated tubers, little is known about the proximate composition and reasons to expect that some of the species differ in composition from common varieties. Furthermore, several species of cassava also have two cyanogenic glycosides, linamarin and a small amount of lotaustralin, which are catalytically hydrolyzed to release toxic hydrogen cyanide ( $\mathrm{HCN}$ ) toxic to human beings.

The level of total cyanide contents of different varieties and plant parts of cassava is $1-1550 \mathrm{mg} \mathrm{HCN}$ equivalents / $\mathrm{kg}$ fresh material $=\mathrm{ppm}$, in the root parenchyma and 900 $2000 \mathrm{ppm}$ in the root cortex (peel) [6]. Cassava leaves contain 20-1860 ppm of total cyanide (Bradbury and Denton, 2011). The World Health Organization (WHO) set a safe limit of $10 \mathrm{ppm}$ total cyanide for cassava flour [11]. This maximum limit of has been adopted in different countries for example, $10 \mathrm{ppm}$ for cassava chips by Food Standards Australia and New Zealand [15], while 40 ppm is the limit in
Indonesia [7]. Internationally, the Codex Standard for 'sweet cassava' (those varieties with low levels of cyanogens) is 50 ppm (fresh weight basis, [12], but many countries have yet to formally adopt recommended limits [18].

In spite of its food security and industrial importance, there are no efforts so far done in the nutritional composition; industrial value and information on the biochemical composition of cassava genotypes are scarce. Furthermore, the glycoside attributes of the existing genotypes have never been assessed and the level of anti- nutritional factors on cassava at country level is still unknown; which hinders the wider utilization and researchers to access the biochemical composition of cassava in the country. Cognizant of these facts, the present study was designed to evaluate the yield, hydrogen cyanide and starch contents of cassava genotypes collected from Southwest Ethiopia for use and conservation.

\section{Materials and Methods}

\subsection{Study Areas}

A field studies were conducted during the 2015/16 and 2016/17 growing seasons at Jimma, Tepi and Metu agricultural research centers. The detail descriptions of tested sites are presented (Table 1).

Table 1. The geographical description of the study sites.

\begin{tabular}{llllll}
\hline Location & \multirow{2}{*}{ Altitude (m.a.s.l.) } & Latitude & Longitude & Rainfall (mm) & \multicolumn{2}{c}{ Temperature $\left({ }^{\circ} \mathbf{C}\right)$} & Maximum & Minimum \\
\hline Jimma & 1753 & $7^{0} 40.00^{\prime} \mathrm{N}$ & $36^{0} 47^{\prime} .00^{\prime} \mathrm{E}$ & 1521.1 & 26.2 \\
Metu & 1550 & $8^{0} 18^{\prime} .00^{\prime} \mathrm{N}$ & $35^{0} 35^{\prime} .00^{\prime} \mathrm{E}$ & 1520 & 12.1 \\
Tepi & 1200 & $7^{0} 3^{\prime} .00^{\prime} \mathrm{N}$ & $35^{0} 18^{\prime} .00^{\prime} \mathrm{E}$ & 1685.9 & 12.2 \\
\hline
\end{tabular}

Source: JARC, 2010

\subsection{Plant Materials, Experimental Design and Management}

A total of 11 cassava genotypes were collected from major growing areas of Southwest Ethiopia. The experiment was laid out in randomized complete block design (RCBD) with three replications. The gross plot size for each treatment was $4 \mathrm{~m} \times 4 \mathrm{~m}$, using inter-row spacing of $1.5 \mathrm{~m}$ and intra-rows spacing of $1 \mathrm{~m}$. Cuttings of the same size and age were used as planting material. One month after planting, seedlings were earthed up followed by frequent weeding. All other agronomic practices were followed according to the recommendations.

\subsection{Data Collection}

Data were collected from six plants from each plot and the average values were used for data analysis. The characters that are used for data collection were: tuber length $(\mathrm{cm})$, tuber fresh weight $(\mathrm{t} / \mathrm{ha})$, hydrogen cyanide content $(\mathrm{mg} / \mathrm{kg}$ fresh storage sample) and starch content (\% fresh storage sample) and tuber dry weight ( $\mathrm{t} / \mathrm{ha})$.

\subsubsection{Determination of Starch Content}

The starch content was determined by a modified method of [3]. A cassava storage tuber was collected from tested materials from each location. $500 \mathrm{~g}$ of fresh storage tuber was taken from the distal, middle and apical sections of washed tubers from each of the middle four plants randomly. After peeling, the tuber cut into small pieces with stainless steel knife and then milled using an electric grinder, to obtain fine powder cassava flour. The starch particle was isolated using excess pure water. The slurry was filtered through $1 \mathrm{~mm}$ sieve mesh. The residue was washed three times with $500 \mathrm{ml}$ of water each time to remove remnants of starch. The filtered was allowed to settle for 2 hours for each wash before decanting the liquid. Hence, starch was suspended and nonstarch materials removed by decanting the supernatant. Subsequently, the starch was dried in oven at $30-33^{\circ} \mathrm{C}$ until constant weight attained and dried. The amount of dried starch obtained from one $\mathrm{kg}$ of fresh cassava tuberous roots was weighted and expressed as a percent of the fresh storage tuberous.

\subsubsection{Determination of Hydrogen Cyanide Content}

Determination of hydrogen cyanide contents (HCN $\mathrm{mg} / \mathrm{Kg}$ ). The duplicate samples were harvested from the fields and transported immediately to the laboratory (Food and nutritional laboratory Addis Ababa). The collected 
samples were cleaned, peeled and washed with potable water. Samples from the distal, middle and apical sections of peeled tubers were cut into cube. The acid titration method [2] for the determination of hydrocyanic acid in beans was used. One hundred (100) $\mathrm{ml}$ of $\mathrm{H}_{2} \mathrm{O}$ was added to $25 \mathrm{~g}$ of the sample in a $500 \mathrm{ml} \mathrm{Kjedahl} \mathrm{flask} \mathrm{for} \mathrm{steam} \mathrm{distillation.} \mathrm{The}$ distillate was collected in $20 \mathrm{ml} 0.02 \mathrm{~N}$. $\mathrm{AgNO}_{3}$ acidified with $1 \mathrm{ml} \mathrm{HNO}$. The apparatus was adjusted so that the tip of the condenser dipped below the surface of the liquid in the receiver. After $150 \mathrm{ml}$ had passed over, excess $\mathrm{AgNO}_{3}$ was titrated with $0.02 \mathrm{KSCN}$ using $\mathrm{Fe}$ alum an indicator. The results were calculated as fresh matter basis as follows:

$$
\begin{aligned}
100 / \mathrm{W} \times 0.27)] \times\left[\left(\mathrm{VAgNO}_{3}\right.\right. & =\text { sample } \mathrm{HCN} / 100 \mathrm{~g} \mathrm{mg} \\
1 \mathrm{ml} \text { of } 0.01 \mathrm{~N} \mathrm{AgNO}_{3} & =0.27 \mathrm{mg} \text { of } \mathrm{HCN}
\end{aligned}
$$

Where: $\mathrm{VAgNO}_{3}$ Volume of silver nitrate $=[(20-(2 \times \mathrm{V}$ $\mathrm{KSCN})$ )]

$\mathrm{V}$ KSCN Volume of potassium thiocyanate consumed in and $\mathrm{W}$ : weight of sample

\subsection{Data Analysis}

The collected data were analyzed by using SAS statistical Software package [25]. Both quantitative and quality data were subjected to analysis of variance (ANOVA) using the RCBD procedure as suggested by [17]. Means were separated using the Least Significant Difference (LSD) procedure at the $5 \%$ and $1 \%$ level of significance.

\section{Results}

\subsection{Mean Performance of Storage Tuber and Length}

The mean storage tuber yield ( $\mathrm{t} / \mathrm{ha}$ ), storage tuber length (cm) hydrogen cyanide $(\mathrm{mg} / \mathrm{kg}$ fresh tuber weight) and starch contents $(\%)$ of tested cassava genotypes and locations are presented in Table 1 . The result of the study revealed that there were significant $(\mathrm{p}<0.05)$ differences among cassava genotypes collected from southwest Ethiopia. Based on combined mean performance of Jimma, genotype AAGT-108 (70.54 t/ha), AAGT-189 (61.49 t/ha) and AAGT 192 (61.45 $\mathrm{t} / \mathrm{ha}$ ) were produced the highest storage tuber yield. Similarly, genotype AAGT-108, AAGT-192, AAGT-028 and AAGT189 gave the highest performance at Metu and Tepi with storage tuber yield of $77.8 \mathrm{t} / \mathrm{ha}, 76.4 \mathrm{t} / \mathrm{ha}, 74.15 \mathrm{t} / \mathrm{ha}$ and 58.6 $\mathrm{t} / \mathrm{ha}$, and $78.55,66.78,72.99$, and $77.59 \mathrm{t} / \mathrm{ha}$, respectively. Likewise, storage tuber length of tested genotypes and locations showed similar trends as storage tuber yield. Genotypes AAGT-189, AAGT-108 and AAGT-191 produced the longest storage tuber with 56.75, 52.40 and $52.90 \mathrm{~cm}$, respectively. However, released varieties Qulle and Kello provided the longest storage tube at Metu and Tepi. Based on overall performance genotypes AAGT-028, AAGT-189 and AAGT-192 are the best performed genotypes in all tested locations.

\subsection{Mean Performance of Hydrogen Cyanide and Starch Content}

The mean hydrogen cyanide and starch contents are important quality parameter in cassava breeding. In this study, genotypes AAGT-108, AAGT-189 and AAGT-192 produced the highest mean hydrogen cyanide contents with value of $105.35,118.5$ and $11.7 \mathrm{mg} / \mathrm{kg}$ of fresh tuber for Jimma, $71.05,75.50$ and $76.05 \mathrm{mg} / \mathrm{kg}$ fresh sample for Metu and $128.35,88.35$ and $76.25 \mathrm{mg} / \mathrm{kg}$ for Tepi, respectively. The starch contents of established genotypes with tested locations are presented in Table 2. At Jimma, genotypes AAGT-108, AAGT-189 and AAGT-192 are the best materials as compared to others and gave the mean starch content of $15.22,16.98$ and $16.61 \%$ per one $\mathrm{kg}$ of fresh storage tuber cassava sample. Similarly, the genotype performed well at Metu and Tepi with the value of $10.18,10.83$ and $10.91 \%$ at Metu and 18.4, 12.7 and $15.65 \%$ per kilogram of fresh storage tuber cassava sample, respectively.

\begin{tabular}{|c|c|c|c|c|c|c|c|c|c|c|c|c|c|c|c|c|c|c|}
\hline \multirow{3}{*}{ Genotypes } & \multicolumn{9}{|c|}{ Storage tuber yield (t/ha) } & \multicolumn{9}{|c|}{ Storage tuber length $(\mathrm{cm})$} \\
\hline & \multicolumn{3}{|c|}{ Jimma } & \multicolumn{3}{|l|}{ Metu } & \multicolumn{3}{|l|}{ Tepi } & \multicolumn{3}{|c|}{ Jimma } & \multicolumn{3}{|l|}{ Metu } & \multicolumn{3}{|l|}{ Tepi } \\
\hline & 2015 & 2017 & Mean & 2015 & 2017 & Mean & 2015 & 2017 & Mean & 2015 & 2017 & Mean & 2015 & 2017 & Mean & 2015 & 2017 & Mean \\
\hline Kello & 48.01 & 44.4 & 46.21 & 75.7 & 34.4 & 55.05 & 77.71 & 31.18 & 54.45 & 44.0 & 53.4 & 48.70 & 47.3 & 43.4 & 45.35 & 30.9 & 38.8 & 34.85 \\
\hline $45 / 72 \mathrm{NR}$ & 62.01 & 54.9 & 58.46 & 53.3 & 41.3 & 47.30 & 37.92 & 77.60 & 57.76 & 45.0 & 45.7 & 45.35 & 46.0 & 34.8 & 40.40 & 31.8 & 34.0 & 32.90 \\
\hline $45 / 72 \mathrm{NW}$ & 51.41 & 54.5 & 52.96 & 54.1 & 58.5 & 56.30 & 77.46 & 75.75 & 76.61 & 43.3 & 53.5 & 48.40 & 39.7 & 35.8 & 37.75 & 32.5 & 40.5 & 36.50 \\
\hline AAGT 028 & 38.50 & 39.9 & 39.20 & 80.1 & 68.2 & 74.15 & 68.42 & 77.56 & 72.99 & 47.3 & 46.3 & 46.80 & 39.3 & 36.5 & 37.90 & 27.6 & 41.3 & 34.45 \\
\hline AAGT 108 & 73.38 & 67.7 & 70.54 & 78.4 & 77.2 & 77.80 & 79.59 & 77.51 & 78.55 & 51.0 & 53.8 & 52.40 & 41.7 & 44.2 & 42.95 & 28.9 & 51.9 & 40.40 \\
\hline AAGT 189 & 58.48 & 64.5 & 61.49 & 45.1 & 72.1 & 58.60 & 76.71 & 78.46 & 77.59 & 58.0 & 55.5 & 56.75 & 35.0 & 52.2 & 43.60 & 29.7 & 37.8 & 33.75 \\
\hline AAGT 191 & 47.38 & 52.2 & 49.79 & 65.4 & 78.9 & 72.15 & 64.58 & 53.99 & 59.29 & 56.0 & 49.8 & 52.90 & 40.7 & 38.5 & 39.60 & 27.1 & 31.9 & 29.50 \\
\hline AAGT 192 & 74.40 & 48.5 & 61.45 & 80.6 & 72.2 & 76.40 & 51.88 & 81.67 & 66.78 & 47.0 & 49.4 & 48.20 & 44.7 & 46.0 & 45.35 & 31.1 & 37.9 & 34.50 \\
\hline AAGT 200 & 52.50 & 67.3 & 59.90 & 74.2 & 62.1 & 68.15 & 64.84 & 50.48 & 57.66 & 61.0 & 45.4 & 53.20 & 35.0 & 41.9 & 38.45 & 30.9 & 34.5 & 32.70 \\
\hline Mean & 55.95 & 56.44 & 56.20 & 66.7 & 59.2 & 62.95 & 67.4 & 64.1 & 65.75 & 49.8 & 50.3 & 50.05 & 42.5 & 42.5 & 42.50 & 30.3 & 38.2 & 34.25 \\
\hline LSD (5\%) & 7.17 & 19.1 & 12.71 & 37.2 & 21.1 & 11.87 & 17.18 & 25.67 & 17.93 & 19.5 & 13.7 & 8.71 & 16.2 & 11.8 & 9.14 & 6.2 & 8.6 & 7.41 \\
\hline
\end{tabular}

Table 2. Mean fresh storage tuber yield $(\mathrm{t} / \mathrm{ha}$ ) and tuber length $(\mathrm{cm})$ of cassava genotypes of in tested locations and years. 
Table 3. The mean hydrogen cyanide content $(H C N \mathrm{mg} / \mathrm{kg}$ ) and starch content (\%) from one $\mathrm{kg}$. fresh tuber sample of cassava genotypes over locations and years.

\begin{tabular}{|c|c|c|c|c|c|c|c|c|c|c|c|c|c|c|c|c|c|c|}
\hline \multirow{3}{*}{ Genotypes } & \multicolumn{9}{|c|}{ Hydrogen cyanide contents } & \multicolumn{9}{|c|}{ Starch content $(\%)$} \\
\hline & \multicolumn{3}{|c|}{ Jimma } & \multicolumn{3}{|l|}{ Metu } & \multicolumn{3}{|l|}{ Tepi } & \multicolumn{3}{|c|}{ Jimma } & \multicolumn{3}{|l|}{ Metu } & \multicolumn{3}{|l|}{ Tepi } \\
\hline & 2015 & 2017 & Mean & 2015 & 2017 & Mean & 2015 & 2017 & Mean & 2015 & 2017 & Mean & 2015 & 2017 & Mean & 2015 & 2017 & Mean \\
\hline Qulle & 51.10 & 52.73 & 51.9 & 28.9 & 42.30 & 35.6 & 59.2 & 56.70 & 57.95 & 7.33 & 7.57 & 7.45 & 4.15 & 6.07 & 5.11 & 8.49 & 8.14 & 8.32 \\
\hline Kello & 55.00 & 42.87 & 48.9 & 56.7 & 54.80 & 55.75 & 67.3 & 47.80 & 57.55 & 7.89 & 6.15 & 7.02 & 8.14 & 7.86 & 8.00 & 9.66 & 6.86 & 8.26 \\
\hline $45 / 72 \mathrm{NR}$ & 77.90 & 56.70 & 67.3 & 39.1 & 46.70 & 42.9 & 80.8 & 76.40 & 78.6 & 11.18 & 8.14 & 9.66 & 5.61 & 6.70 & 6.16 & 11.6 & 11.0 & 11.30 \\
\hline $45 / 72 \mathrm{NW}$ & 59.30 & 60.30 & 59.8 & 47.2 & 50.60 & 48.9 & 72.9 & 80.30 & 76.6 & 8.51 & 8.65 & 8.58 & 6.77 & 7.26 & 7.02 & 10.4 & 11.5 & 10.95 \\
\hline AAGT 028 & 87.50 & 67.50 & 77.5 & 75.6 & 67.30 & 71.45 & 62.0 & 67.10 & 64.55 & 12.55 & 9.68 & 11.12 & 10.8 & 9.66 & 10.23 & 8.90 & 9.63 & 9.27 \\
\hline AAGT 108 & 113.1 & 98.75 & 105.9 & 52.6 & 89.50 & 71.05 & 148.4 & 108.3 & 128.35 & 16.23 & 14.2 & 15.22 & 7.55 & 12.8 & 10.18 & 21.3 & 15.5 & 18.40 \\
\hline AAGT 189 & 128.6 & 108.4 & 118.5 & 52.6 & 98.40 & 75.5 & 77.90 & 98.80 & 88.35 & 18.45 & 15.5 & 16.98 & 7.55 & 14.1 & 10.83 & 11.2 & 14.2 & 12.70 \\
\hline AAGT 191 & 66.00 & 59.20 & 62.6 & 98.6 & 79.20 & 88.9 & 59.40 & 52.70 & 56.05 & 9.47 & 8.49 & 8.98 & 14.1 & 11.3 & 12.70 & 8.52 & 7.56 & 8.04 \\
\hline AAGT 192 & 118.6 & 112.8 & 115.7 & 59.3 & 92.80 & 76.05 & 115.8 & 102.4 & 109.1 & 17.02 & 16.2 & 16.61 & 8.51 & 13.3 & 10.91 & 16.6 & 14.7 & 15.65 \\
\hline AAGT 200 & 66.90 & 44.70 & 55.8 & 64.8 & 44.00 & 54.4 & 62.00 & 52.10 & 57.05 & 9.60 & 6.41 & 8.01 & 9.30 & 6.31 & 7.81 & 8.90 & 7.48 & 8.19 \\
\hline Local & 47.90 & 51.10 & 49.5 & 55.3 & 40.50 & 47.9 & 52.40 & 52.40 & 52.4 & 6.87 & 7.33 & 7.10 & 7.93 & 5.81 & 6.87 & 7.52 & 7.52 & 7.52 \\
\hline Mean & 79.26 & 68.65 & 74.0 & 57.3 & 64.19 & 60.76 & 78.01 & 72.27 & 75.14 & 11.37 & 9.85 & 10.61 & 8.23 & 9.21 & 8.72 & 11.2 & 10.3 & 10.75 \\
\hline $\operatorname{LSD}(5 \%)$ & 2.3 & 1.1 & 1.58 & 1.9 & 1.50 & 0.45 & 0.10 & 0.23 & 2.10 & 0.27 & 0.14 & 0.27 & 0.11 & 0.15 & 0.57 & 0.14 & 0.12 & 0.42 \\
\hline
\end{tabular}

\section{Discussion}

In the present study, the mean storage tuber yield showed high significant differences $(p<0.05)$ among cassava genotypes from southwest Ethiopia, this suggested, the presence of high degree of genetic variability in the materials evaluated and the existence of considerable genetic diversity among cassava genotypes for selection. The result of this study is similar with the report of [28] who reported cassava genotypes collected from southwest Ethiopia had significant difference in storage tuber yield and related traits. Similarly, [26] also reported high significant $(\mathrm{p}<0.01)$ difference among cassava genotypes tested at Hawassa, Amaro, Jima and Sekota areas of Ethiopia. The storage tuber length is also vary significantly $(\mathrm{p}<0.05)$ among tested cassava genotypes. The longest tuber length is obtained from genotypes AAGT 189, Qulle, AAGT 108 at Jimma, Metu and Tepi with values of $56.75,53.10$ and $40.40 \mathrm{~cm}$, respectively. The length of tuber is highly affected by the soil texture of cassava grown. This result is supported by the report of [29], who reported the storage tuber length of cassava grown in clay soil and high moisture stress areas of southern Ethiopia are reduced significantly. Besides, [26] reported variety Kello produced longest mean storage tuber of $40.67 \mathrm{~cm}$ grown in major growing areas of Ethiopia. However, in this study the storage tuber length obtained from Jimma (48.90) and Metu (53.10 $\mathrm{cm})$ is higher than the report of [26].

The hydrogen cyanide and starch content are the important quality parameter in cassava breeding. According to [20] and [1], cassava genotypes are classified in two groups, according to the difference on toxicity and palatability of the storage tubers: sweet (slightly sweet; that is, plants that have less than $100 \mathrm{mg} / \mathrm{kg}$ cyanuric acid) or bitter (those have a perceptible bitter taste due to the high concentrations of $\mathrm{HCN}$, that is, values over $100 \mathrm{mg} / \mathrm{kg}$ fresh smple). There is no morphological characteristic that may tell these two groups apart [8]. In the present study, cassava genotypes AAGT 189, AAGT 191 and AAGT 108 produced the highest cyanogenic glycosidecyanide content with value of $118.5,88.9$ and $128.35 \mathrm{mg} / \mathrm{kg}$ fresh sample, respectively. The result obtained from this study was similar with the report of [1], who reported, the cyanide contents ranged from $15-225 \mathrm{mg} / \mathrm{kg}$ of cassava collected from Brazil. On contrarily, the result obtained from this study was higher than the report of [10] reported the cyanide contents of cassava genotypes ranged from 36.65-62.57 grown in Abia state of Nigeria. Similarly, the mean starch contents of cassava genotypes ranged from 5.11-18.4\%. The lowest starch content obtained from genotype Qulle at Metu and the highest mean starch content was collected from genotype AAGT 108 at Tepi. The result obtained from this study was lower than the study of [23] who reported the starch contents ranged from 62-91\%. Similarly, the starch content obtained from in this study almost similar with the study of [10] reported the starch contents of five cassava genotypes from Nigeria ranged from $17.48-20.62 \%$.

\section{Conclusion and Recommendation}

The yields of cassava are highly affected by genotype and location (environment) which indicated the yields and quality performance of genotypes varies from one location to another. Similarly, the hydrogen cyanide content also varied from one location to other within and among genotypes. Based on the overall mean result of hydrogen cyanide and starch contents, genotype AAGT-108 (128.35mg/kg) and AAGT-189 (118.5 $\mathrm{mg} / \mathrm{kg}$ ) are recommended for bitter type (high HCN content). As a result, the National Variety Release Committee officially released genotype AAGT-108 (Melko-108) as bitter type for production. On contrary, the rest of genotypes have sweet type due to its cyanide content below $100 \mathrm{mg} / \mathrm{kg}$ and are recommended for human consumption after full processing. 


\section{Acknowledgements}

The authors would like to acknowledge Ethiopian Institute of Agricultural Research/Jimma Agricultural Research Center (JARC) for the financial support of this study. The Authors also extend their acknowledgement for the collaborating agricultural research center (Tepi) for their implementation of national variety and eventually the verification trial.

\section{References}

[1] André R. F., Maria A. N, Almir J. R. Caroline P, Jeandro A, Tamires B, Rosilene K, Luis A. B. L, and Helenice DS. S. 2016. Cassava Flour: Quantification of Cyanide Content. Food and Nutrition Sciences, 7, 592-599.

[2] AOAC, 2005. Association of Official Agricultural Chemist, Official Methods of Analysis, $17^{\text {th }}$ edn, Vol. 1 and 2. Horowitz edition intern, Maryland, USA. Washington DC. USA.

[3] Ashoka MJ and Richard JE. 1992. Effects of cultivar and growth stage on the gelatinization properties of cassava (Manihot esculanta Cratz) starch. J. Sci. Agri. 59: 53-58.

[4] Bokanga, M., 1999. Cassava: Post-harvest operations. Information Network on Post-Harvest Operations. In PostHarvest Compendium, pp. 1-26.

[5] Bradbury J. H., Denton, I. C. 2011. Mild methods of processing cassava leaves to remove cyanogens and conserve key nutrients. Food Chemistry (in press).

[6] Cardoso A. P., Mirione E., Ernesto M., Massaza F., Cliff J., Haque, M. R. and Bradbury J. H. 2005. Processing of cassava roots to remove cyanogens. Journal of Food Composition and Analysis, 18, 451-460.

[7] Djazuli M. and Bradbury J. H. 1999. Cyanogen content of cassava roots and flour in Indonesia. Food Chemistry, 65, 523-525.

[8] Dufour D. L. 1988 Cyanide Content of Cassava (Manihot esculenta, Euphorbiaceae) Cultivars Used by Tukanoan Indians in Northwest Amazonia. Economic Botany, 42, 255266. http://dx.doi.org/10.1007/BF02858929

[9] El-Sharkawy, M. A. 1993. Drought-tolerant cassava for Africa, Asia, and Latin America, Bioscience, 43: 441-451.

[10] Ezeigbo O R., Ukabi C F., Ike-Amadi A. and Ekaiko M. U. 2015. Determination of Starch and Cyanide Contents of Different Species of Fresh Cassava Tuber in Abia State, Nigeria. British Biotechnology Journal, 6: 10-15.

[11] FAO/WHO. 1995. Codex standard for edible cassava flour. Codex Standard 176-1989. Rome, Italy: Food and Agriculture Organisation and World Health Organisation of the United Nations.

[12] FAO/WHO. 2005. Codex standard for sweet cassava. Codex Standard 238-2003. Rome: Food and Agriculture Organisation and World Health Organisation of the United Nations.

[13] FAO. 2010. The world cassava economy: facts, trends and outlooks. Rome: Food and Agriculture Organization of the United Nations and International Fund for Agricultural Development.

[14] FAO. (Food And Agriculture Organization of The United
Nation) 2013. Save and grow: Cassava. A guide to sustainable production intensification.

[15] Fsanz 2009. Proposal P 1002 Hydrocyanic Acid in Ready-toEat Cassava Chips, First Review Report. Food Standards Australia New Zealand.

[16] Getachew W., Tewodros M. and Taye K.. 2012. Postharvest handling utilization and food preparation of cassava in Amharic Version. Ethiopian Institute of Agricultural Research, Addis Ababa, Ethiopia.

[17] Gomez, KA., Gomez, AA., 1984. Statistical Procedures for Agricultural Research. 2nd ed. John Wiley and Sons, inc., New York.

[18] Kolind-H, L. and Brimer L. 2009. The retail market for fresh cassava root tubers in the European Union (EU): the case of Copenhagen, Denmark - a chemical food safety issue? Journal of the Science of Food and Agriculture, 90, 252-256.

[19] Lebot V. 2009. Tropical root and tuber crops: cassava, sweet potato, yams and aroids. Wallingford, UK: CABI.

[20] Montagnac J, Davis C and Tanumihardjo S. 2009. Processing techniques to reduce toxicity and anti-nutrients of cassava for use as a staple food. Comprehensive review in food science and food safety. 8: 1-8.

[21] Nhassico D., Muquingue H., Cliff J., Cumbana A. and Bradbury J. H. 2008. Rising African cassava production, diseases due to high cyanide intake and control measures. Journal of the Science of Food and Agriculture, 88, 2043-2049.

[22] Nweke F., Spencer D. and Lynam J. 2002. The cassava transformation: Africas best kept secret.

[23] Muleta F and Mohammed A. 2017. Determining of cyanide concentration levels in different cassava varieties in selected iodine deficiency disorded (IDD) areas of wolaita zone, southern Ethiopia. Journal of natural sciences research. 7: 3.

[24] Serge S., Traore S. and Brou K. 2013. Assessment of cyanide content in cassava (manihot esculenta crantz) varieties and derived products from Senegal. International journal of nutrition and food sciences 2: 5, 225-231.

[25] SAS, Institute. 2000. Statistical Analytical Systems SAS / STAT user's guide version, 8 cary NC: SAS institute inc.

[26] Tesfaye T., Bekele A., Tsegaye E., Getachew W., Tewodros M., Beshir W and Messele G. 2017. Performance of cassava (Manihot esculanta Cratz) clones in potential and low moisture stressed areas of Ethiopia. African Journal of Agricultural Research, 12: 1738-1746.

[27] Tewodros M. and Biruke A.. 2012. Cassava (Mannihot esculenta Cranz) Varieties and Harvesting Stages Influenced Yield and Yield Related Components. IISTE, Journal of Natural Science Research,. 2: 122-128.

[28] Tewodros M. and Getachew W. 2013. Evaluation of the Adaptability and Acceptability of improved Cassava (Manihot esculenta Crantz) varieties in Southwest Ethiopia. Greener Journal of Agricultural Sciences, 3: 658-662.

[29] Tewodros M. and Yared D. 2015. Farmers appraisal, manifestation and scaling up of improved cassava technologies in moisture stressed areas of the Southern Ethiopia. Journal of Genetic and Environmental Resources Conservation, 2015, 3: 100-105. 
[30] Tewodros Mulualem and Zelalem Bekeko. 2015. Assessment of conventional breeding on cassava and its physiological adaptive mechanisms: Implication for moisture stress. Asian Journal of Agricultural Research, 9: 38-54. 